\title{
Joubert syndrome
}

INSERM

\section{Source}

INSERM. (1999). Orphanet: an online rare disease and orphan drug data base. Joubert syndrome. ORPHA:475

Joubert syndrome (JS) is characterized by congenital malformation of the brainstem and agenesis or hypoplasia of the cerebellar vermis leading to an abnormal respiratory pattern, nystagmus, hypotonia, ataxia, and delay in achieving motor milestones. 